\title{
Elucidation of Gene Interaction Networks Through Time-Lagged Correlation Analysis of Transcriptional Data
}

\author{
William A. Schmitt Jr., R. Michael Raab, and Gregory Stephanopoulos ${ }^{1}$ \\ Department of Chemical Engineering, Massachusetts Institute of Technology, Cambridge, Massachusetts 02139, USA
}

\begin{abstract}
The photosynthetic cyanobacterium Synechocystis sp. strain PCC 6803 uses a complex genetic program to control its physiological response to alternating light conditions. To study this regulatory program time-series experiments were conducted by exposing Synechocystis sp. to serial perturbations in light intensity. In each experiment whole-genome DNA microarrays were used to monitor gene transcription in 20-min intervals over 8- and 16-h periods. The data was analyzed using time-lagged correlation analysis, which identifies genetic interaction networks by constructing correlations between time-shifted transcription profiles with different levels of statistical confidence. These networks allow inference of putative cause-effect relationships among the organism's genes. Using light intensity as our initial input signal, we identified six groups of genes whose time-lagged profiles possessed significant correlation, or anti-correlation, with the light intensity. We expanded this network by using the average profile from each group of genes as a seed, and searching for other genes whose time-lagged profiles possessed significant correlation, or anti-correlation, with the group's average profile. The final network comprised 50 different groups containing 259 genes. Several of these gene groups possess known light-stimulated gene clusters, such as Synechocystis sp. photosystems I and II and carbon dioxide fixation pathways, while others represent novel findings in this work.
\end{abstract}

The DNA microarray has become an established tool for the parallel monitoring of gene expression profiles. Most common experimental design strategies observe static gene expression differences between conditions, such as disease versus nondisease case comparisons. While such experiments generate information for diagnostic applications, they are not well suited for uncovering the roles of these genes in the larger context of cellular regulation.

Dynamic transcriptional data allow the formation of gene clusters with similar temporal expression profiles. The various forms of clustering (Eisen et al. 1998; Alter et al. 2000; Holter et al. 2000) employed to date have produced valuable information, including potential gene relationships and the identity of transcription factor binding motifs. These methods, however, are limited in their ability to infer causality or directional relationships between genes. The results of clustering algorithms often yield relations such as "gene A is a good predictor of gene B," which is an equivalent statement to "gene B is a good predictor of gene A." Neither Bayesian networks (Friedman et al. 2000), nor information theory-based approaches (Somogyi and Fuhrman 1997) have made use of the sequential nature of time-series data in current applications. Conversely, when enough time points are available to prevent over fitting the data and find statistically significant correlations, a discovery method to uncover potential causal relationships among genes may be attempted. Directionality can be added to these probabilistic networks by determining the temporal order in which gene expression patterns are affected in a sequence.

Consider Figure 1 in which an input signal, such as light intensity, affects the transcription of a pair of genes through a cascade from gene 1 to gene 2 . In an experiment that only mea-

\footnotetext{
'Corresponding author.

E-MAIL gregstep@mit.edu; FAX (617) 253-3122.

Article and publication are at http://www.genome.org/cgi/doi/10.1101/ gr.2439804.
}

sures static gene expression values at each input signal intensity, the best conclusion that might be drawn from such data is that the genes are somehow related. On the other hand, if dynamic experiments are conducted that allow the observation of delayed responses, then it is possible to extract additional information from these measurements pointing to potential directionality.

A relatively complete picture of transcriptional regulatory behavior should be possible by probing the transcriptional dynamics of carefully designed experiments covering a wide range of conditions. Dynamic experiments that sequentially vary external parameters offer insights into how cellular physiology depends on changing environmental conditions. Time-lagged correlation analysis is one method that can be applied to infer putative causal relationships between system perturbations and system responses.

Linear Pearson correlations have been used to identify genes that are coexpressed or antiexpressed for clustering purposes (D'Haeseleer et al. 1998; Kuruvilla et al. 2002). Time-lagged correlations extend this technique by determining the best correlations among profiles shifted in time. For a transcription profile represented by a series of $n$ measurements taken at equally spaced time points, the correlation between genes $i$ and $j$ with a time lag, $\tau$, is $\mathbf{R}(\tau)=\left(r_{i j}(\tau)\right)$, defined by

$$
\begin{gathered}
S_{i j}(\tau)=\left\langle\left(x_{i}(t)-\bar{x}_{i}\right)\left(x_{j}(t+\tau)-\bar{x}_{j}\right)\right\rangle \\
r_{i j}(\tau)=\frac{S_{i j}(\tau)}{\sqrt{S_{i i}(\tau) S_{j j}(\tau)}}
\end{gathered}
$$

where $x_{i}(t)$ denotes the expression of gene $i$ at time $t, \bar{x}_{\mathrm{i}}$ is the expression value of gene $i$ averaged across all time points, and the angled brackets represent the inner product between the timeshifted profiles. The matrix of lagged correlations $\mathbf{R}(\tau)$ can be used to rank the correlation and anticorrelation between genes through conversion to a Euclidean distance metric, $d_{i j}$ :

$$
d_{i j}=\left(c_{i i}-2 c_{i j}+c_{i j}\right)^{1 / 2}=\sqrt{2}\left(1.0-c_{i j}\right)^{1 / 2}
$$




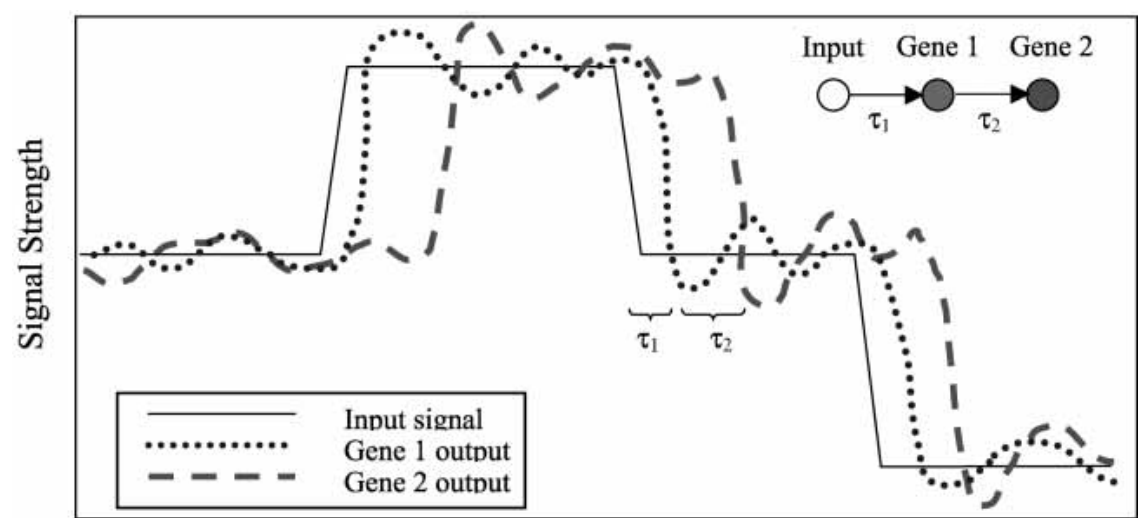

Time

Figure 1 Idealized gene expression experimental results, where measurable time lags $\tau_{1}$ and $\tau_{2}$ are indicative of the underlying cascade of biochemical reactions which lead to the input signal's effect on the genes.

$$
c_{i j}=\max _{\tau}\left|r_{i j}(\tau)\right|
$$

where, $c_{i j}$ is the maximum absolute value of the correlation between two genes with a time lag $\tau$. If the value of $\tau$ that gives the maximum correlation is 0 , then the two genes are best correlated with no time lag. The matrix $\mathbf{D}=\left(\mathrm{d}_{\mathrm{ij}}\right)$ describes the correlation between two genes, $i$ and $j$, in terms of "distance" by making genes that are least correlated (for any $\tau$ ) the "farthest" apart (Arkin and Ross 1995). Thus by transforming the correlation matrix, $\mathbf{R}$, into a distance matrix, $\mathbf{D}$, we are able to include highly anticorrelated genes, in addition to correlated genes, in the network. By finding genes that are closely related and then examining the corresponding value of $\tau$, an underlying network of potential cause and effect relationships can be elucidated. Some caution is needed to ensure genes with high correlation have been chosen using enough data points to give statistical significance, otherwise all of the $\tau$ values used will merely overfit the data. Such errors may be obvious if values for $\tau$ are unreasonably long from a biological standpoint.

Arkin, Shen, and Ross (1997) previously used time-lagged correlations to "reconstruct" the reaction network of central carbon metabolism by placing eight major enzymes and 14 chemical components into a continuous stirred tank reactor and inducing dynamic concentration shifts of the chemical species. Concentrations of the major chemical species were measured throughout the experiment, while the input concentrations of citrate and adenosine monophosphate (AMP) were periodically adjusted to keep the system away from steady-state. Using time-lagged correlations to analyze the output data, these authors were able to recreate most of the features from the original pathway; however, some of the interactions were not recovered in the reconstruction attempt. For example the inhibitory impact of citrate on the conversion of fructose-6phosphate (F6P) to fructose 1,6bisphosphate (F16BP) was not included. Furthermore, species that are not controlled or measured cannot be placed in the network. Despite these drawbacks, this example showed that even when the specific method of interaction is unknown or unmeasured, useful information could be inferred about the overall structure of a network from forced dynamic experiments.

By sequencing the Synechocystis genome (Kaneko et al. 1996), it is now possible to begin investigating the systemic properties of the organism. As a model system, increasing interest in the cyanobacterium Synechocystis PCC6803 has focused on the organism's ability to synthesize various chemicals such as polyhydroxyalkanoate (PHA) biopolymers. Coupled with the cyanobacterium's $\mathrm{CO}_{2}$ fixation ability, Synechocystis represents a potentially useful biocatalyst for the conversion of $\mathrm{CO}_{2}$ gas emissions into value-added materials. On the other hand, the organism suffers from a relatively slow growth rate and low PHA yields, which create economic hurdles that must be overcome before its implementation in commercial processes. Understanding, and subsequently improving, network properties may help alleviate these obstacles, enabling the carbon-fixing and product forming potential of Synechocystis to be exploited for industrial purposes.

In this work we identified a network of putative directional interactions between cascades of genes by using time-lagged correlation analysis. This network relates the changing light input signal to dynamic gene transcription data obtained using full genome DNA microarrays (Schmitt Jr. and Stephanopoulos 2003) in cultures of the cyanobacterium Synechocystis PCC6803. Perturbations in light intensity are easy to implement experimentally and have minimal diffusional time lag. Synechocystis is particularly wellsuited to this type of regulatory analysis because the expression levels of many genes change over a period of $24 \mathrm{~h}$ in response to environmental light changes (Hihara et al. 2001; Gill et al. 2002).

\section{RESULTS}

In the first experiment the culture was exposed to a series of three-step changes in light intensity ranging from 0 to 16 to 90
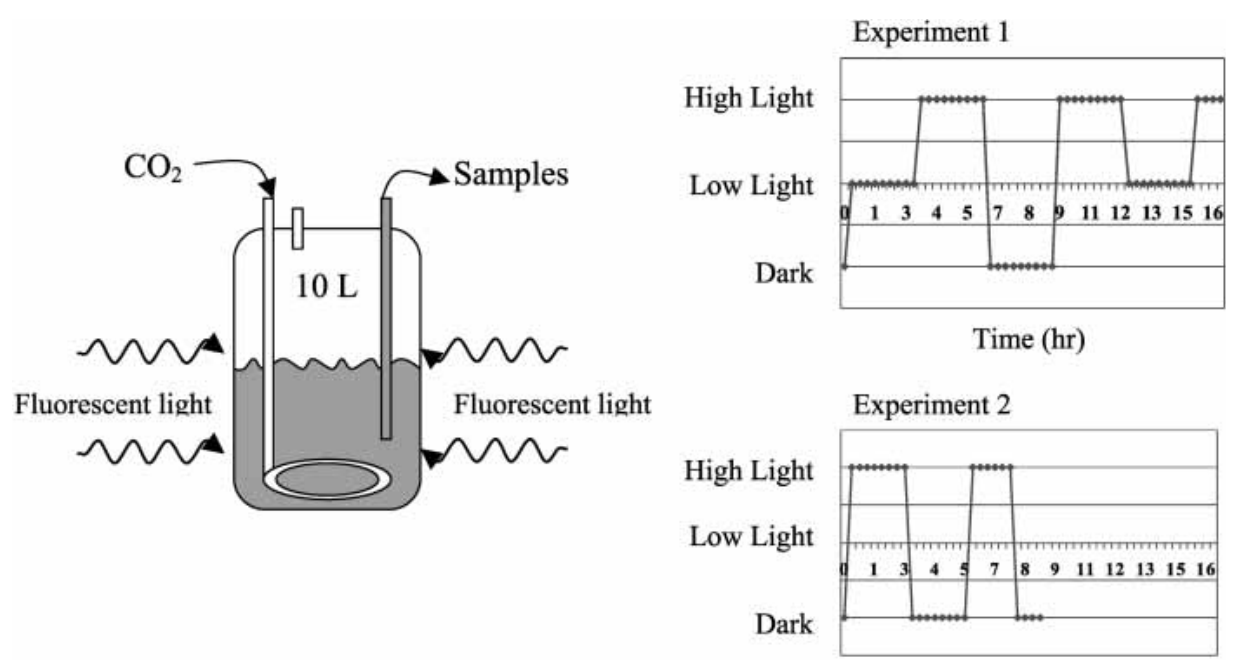

Time (hr)

Figure 2 Experimental set-up and light intensity profiles for both experiments. 
$\mu \mathrm{mol} / \mathrm{m}^{2} / \mathrm{s}$, as shown in Figure 2 . Forty-seven of the fifty samples from this experiment were successfully hybridized to DNA microarrays and provided sufficient signal intensities for further analysis. Two iterations of the time-lagged correlation implementation algorithm were applied to this data. Figure 3 shows 64 genes that were divided among six groups with high correlation directly to the input signal $(|\mathrm{R}|>0.7$ for at least one member of the group), while Figure 4 shows the expansion of this original set to 50 groups comprising 259 genes, using an additional iteration of the algorithm. Both time-lagged correlations (bold arrows) and time-lagged anticorrelations (dotted arrows) are shown, along with zero-lagged correlations (straight lines). Note that genes correlated with no lag to other genes need not necessarily belong in the same group, as they do not show the same degree of correlation with other clusters in the diagram. It is possible that further experiments will confirm their inclusion into a single group, or suggest the elimination of one or both of the two groups.

The annotated genes that respond to the input light signal in a time-lag "wave" are listed in Table 1. Among the transcripts in Table 1, many encode proteins found in the Synechocystis photosystem complexes. For example, genes associated with photosystem I (such as psaE or psaK) and photosystem II (such as $p s b E F L J$ ) seem to become activated at several different time lags relative to the light intensity. Interestingly, this analysis also found both $y c f 3$ and $y c f 48$ having transcriptional expression coordinated with light exposure with the minimum time lag of 20 min. It has been suggested that these genes contribute to either assembly or stability of photosystem I (Wilde et al. 2001) and II (Meurer et al. 1998). The fast response at the transcriptional level of $y c f 3$ and $y c f 48$ to changing light conditions is consistent with these hypotheses. Additionally, Table 1 lists many of the subunits for ATP synthase (such as atpCADFGHI1), which are best correlated with the light intensity at the smallest measurable time lag of $20 \mathrm{~min}$. At least one subunit for the cytochrome complex (pet $G$ ) was also identified.

Other genes that are known to be light-regulated, such as $a p c F$, apcE, and $a p c A B C$ (Gill et al. 2002) also fall into groups with other highly correlated genes. These allophycocyanin genes all possess a time lag of $20 \mathrm{~min}$, while several phycocyanin genes, such as $c p c A B C 2 C 1 D$, have a greater time lag (Table 1; note that $c p c C 1$ was filtered from the original analysis due to low expression ratios, but is in fact well correlated with the other genes listed). Given that the allophycocyanin units make up the core of the phycobilisome structure, while the phycocyanin genes make up the rod-like projections from this core, a model of sequential activation seems plausible and agrees with the transcription of the allophycocyanin genes preceding that of the phycocyanin genes. Furthermore, $c p c G 1$, found at the earliest measured time lag, links the phycocyanin rods to the core allopycocyanin proteins of the phycobilisome (Bryant et al. 1990).

As reported in earlier studies (Watson and Tabita 1996; Hihara et al. 2001; Gill et al. 2002), the sub-units of the carbondioxide fixation complex rubisco $(r b c L, r b c S$, and the potential chaperone protein $r b c X$ ) are shown to be highly correlated with light intensity at the transcriptional level. Other findings, including a homolog of the carbon dioxide concentration unit $\mathrm{ccmK}$ (Watson and Tabita 1996), as well as a handful of genes related to metabolism (icd, gap2, etc.), are also cataloged in Table 1.

In addition to validating the response of known light sensitive genes, some information concerning the roles, and potential interactions, of putative genes can be derived from our analysis. Genes slr0581 and slr0582, were inversely correlated to the light intensity. A homology search using BLAST on these open reading frames (ORFs) suggests no strong homologies with known proteins, so assigning a functional role is difficult. However, slr0582 has at least some similarity with putative binding factors, and therefore may play a role in the transcription of genes regulated as a response to light. Furthermore, slr0581, which had a sufficiently strong signal at every time point to be included in the Principle Component Analysis (Raychaudhuri et al. 2000), has one of the larger loading coefficients determining the shape of Figure 5. This pair of adjacent genes, with operonlike coexpression and a high correlation to light-regulated genes in Synechocystis, requires further study to determine their actual function, but testable hypotheses can be formulated from our work.

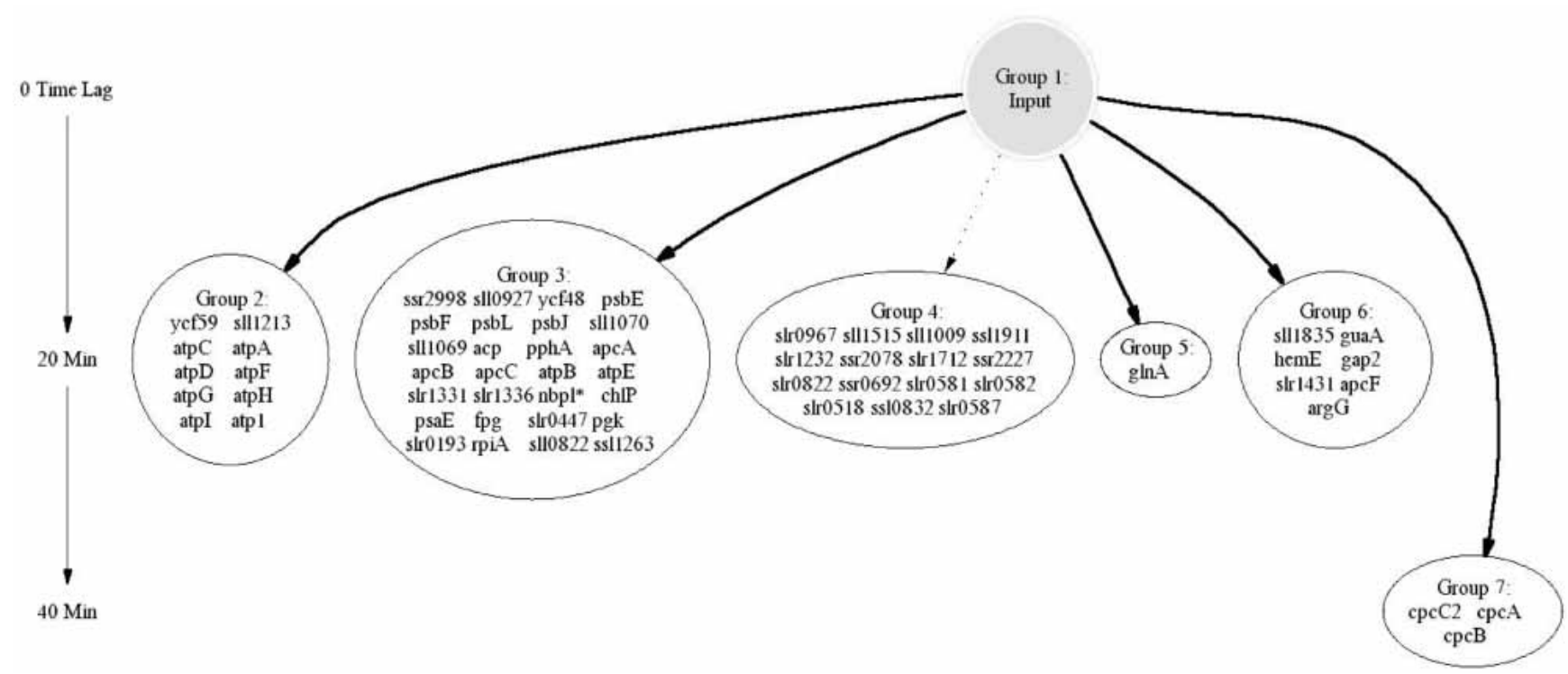

Figure 3 Simplified time-lagged correlation network from Synechocystis sp. PCC6803. The arrows indicate close correlation (|R| $\mid>0.70)$ between groups, and the corresponding numbers indicate the time lag relative to the input. The network is derived from data from Experiment 1. Dashed lines indicate inverse correlation.

\section{Genome Research}

www.genome.org 
Although we used levels of R large enough to minimize the chance of randomly observing highly correlated genes, a second experiment, with a different input light signal (see Fig. 2) was conducted to test the correlations observed in the first experiment. Results for the genes shown in Figure 3 are shown in Table 2. Most of these genes have similar correlations with the input signal in both experiments. Exceptions that have different values between the experiments, could then be used to "prune" or adjust the networks shown in Figures 3 and 4 . Consider, for example, the $c p c$ genes found in Group 7, which seem to correlate less well in the second experiment. Although the correlation is still significant at this level for a time lag of two units (40 min), we also observe a nearly equal correlation at a lag of three units (60 $\mathrm{min}$ ), and further experiments are required to accurately plot these genes within the network. However, unless exceedingly low correlation is observed, such connections cannot reasonably be rejected with only this data, and testing the correlations using complementary techniques would be highly beneficial.

Having conducted two sets of experiments under different input light profiles, the consistency of the measured transcriptional profiles was investigated. One way to do so is by projecting the transcriptional state of the cells in a reduced dimensional space, defined by coordinates that are linear combinations of the gene expression data. In such a space we anticipate that cellular samples taken under similar experimental conditions will cluster together. Principal components analysis (PCA) was used as an unsupervised data visualization tool to test whether cells exposed to the same environmental conditions in different experiments clustered together in the space defined using the first two principle components (Misra et al. 2002) of the combined data sets.

Only genes with expression values for all 74 samples, from both experiments, were considered in the PCA analysis. For these 113 genes, the two largest principle components account for approximately $68.7 \%$ of the variance. Figure 5 shows the 74 samples in a space defined by the two principal components. It can be seen that samples obtained during the "dark" conditions (with a time lag of $20 \mathrm{~min}$ ) reside in an area distinct from those obtained during either of the light conditions in both experiments, with the exception of a single, easily identified outlier point from the second experiment. Not surprisingly, examination of the gene loadings (Misra et al. 2002) used to create Figure 5 shows that many of the genes in the networks of Figures 3 and 4 are key to this distinction (data not shown).

To further substantiate the results of the analysis two sets of simulations were conducted. In the first set of simulations we reanalyzed the data set using only half the data points. Thus instead of having 47 data points at 20-min intervals, we used 24 data points at 40-min intervals. Genes that possessed a maximum correlation value at a time lag of $20 \mathrm{~min}$ in the original data (47 time points) set fell into either the 0 - or 40-min time-lagged group when 40-min sampling intervals were used. Likewise, genes that possessed a maximum correlation value at a time lag of $60 \mathrm{~min}$ in the original data set were placed in either the 40 or $80 \mathrm{~min}$ group. Although some additional genes now pass the $|\mathbf{R}|>0.70$ threshold and enter the analysis, none of the genes that were identified using all 47 time points are eliminated from the analysis when only 24 time points are used. Thus as more time points are used, only the strongest correlations emerge in the analysis. In the second set of simulations we tested the statistical significance of our correlations. To do this we created 10 million sets of random data in the same format as the original data set (47 time points) and found only two samples that had a

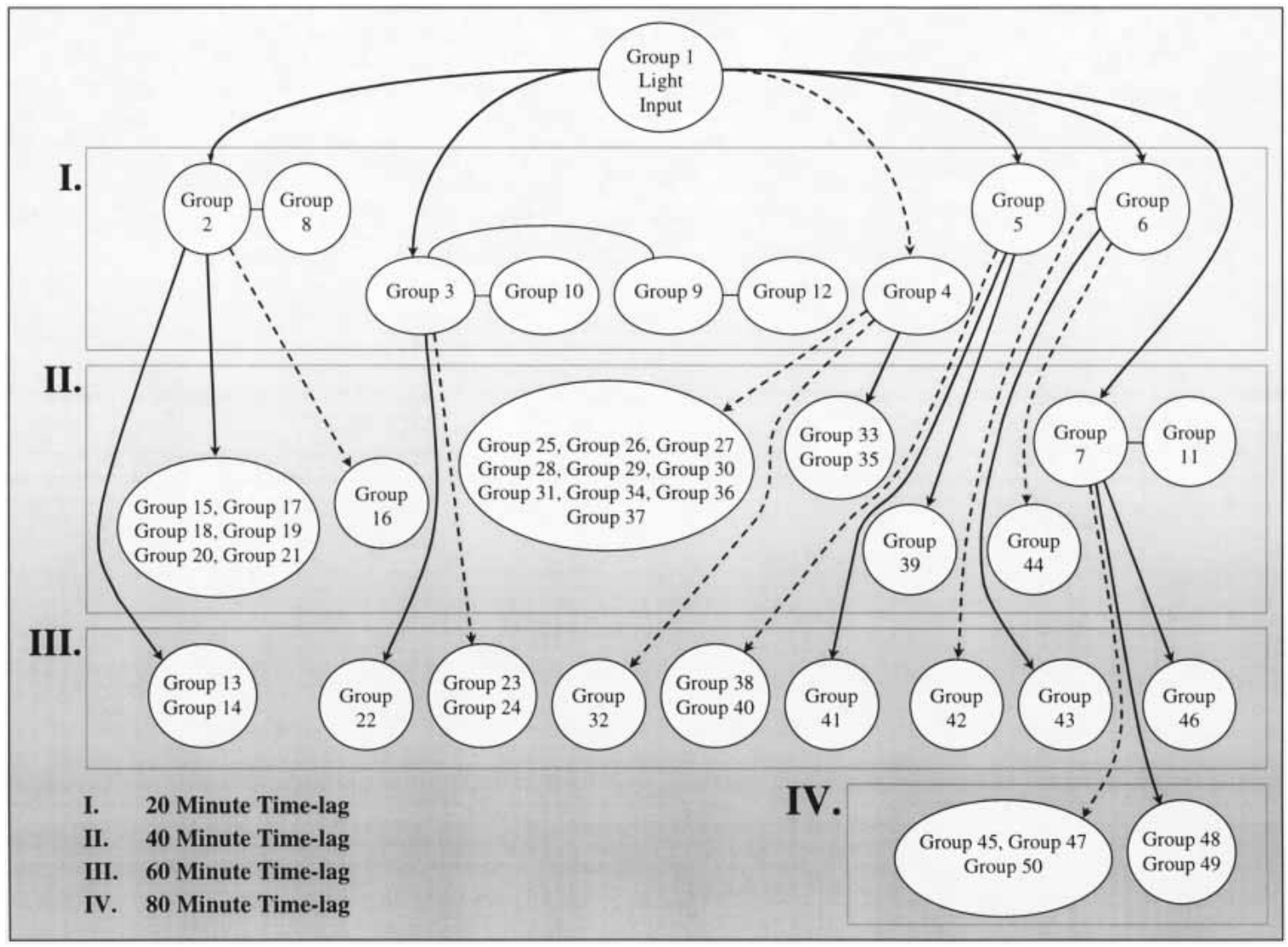

Figure 4 Simplified time-lagged correlation network, second iteration. The genes contained within each group are given in Table 3. 
Table 1. The Expression Intervals at Which Some Characterized Genes Are Correlated (Directly or Indirectly) to the Experimental Light Intensity

\section{0-min time lag}

$a c c B$, efp

atpl,

psaD
cupB

glyA

guaA

ilvC

nirA

ppa

psb), $K$

rpl19,36

$\sec D F$

vals

sll0843

sll1070

s/11515

sll1945

slr0483

sir0582

slr0773

slr0981

slr1051

sir1105

slr1232

slr1331

sir1431

slr1616

slr1623

slr1855

s/r2047

ss 1263

ssr2078

40-min time lag

$\mathrm{ccmK}$

срсA, B, C2

$n d b B$

petF, G

psbl,X

rps21,r

sll0063

sll0096

sll0264

sll1386

sll1979

slr0082

slr0765

sir0921

s/r1821

ss 11046

ssr 1528

60-min time lag

hspA

slr0907

sir1070

sir1396

ss 11792

80-min time lag

hisD

slr2115

acp

bioB

ycf58

ctpA

psaE

gap2

gyrB

murC

pacs

pphA

purD

rps 11, 13

serA

ycf23, 3, 59

sll0927

sll1130

sll1665

sll1951

slr0484

slr0587

slr0776

slr0982

slr1052

slr1 160

sir1237

slr1336

sir1462

sir1617

slr1624

slr2002

s/r2048

ss/1911

ssr2227

gap 1

CpcC 1, D

ndhD1

pppA

ribF

sers

sll0064

sll0103

sll0350

s/11712

slr0038

slr0232

slr0784

slr1282

slr1926

ss/2009

ssr 2130

psbB,M

slr0915

sir1071

sir1410

ycf46

ss 11045

Genes separated by commas indicate that they are located adjacent to one another in the genome.

correlation value of $|\mathbf{R}|>0.70$ for $\tau$ between -40 and $40 \mathrm{~min}$. For uncorrelated data, $|\mathbf{R}|$ follows a t-distribution with $\mathrm{N}-2$ degrees of freedom. In this case $\mathrm{N}=47$, thus the probability of $|\mathbf{R}|>0.70$ by chance is $\ll 0.0001$. This indicates that it is extremely unlikely to observe the correlations identified in this analysis by chance alone.

The three design criteria that need to be considered in planning similar dynamic experiments are the frequency of sampling, the properties of the induced perturbations, and the dynamics of gene transcription. These factors interact with one another and should be optimized to address a specific condition. In these experiments we wanted to study the transcriptional dynamics of Synechocystis sp. in response to light perturbations. Because changes in light intensity can be introduced instantaneously, we were not limited by diffusional effects that may slow the response, or create varying time lags dependent upon the magnitude of the induced change. The induction and relaxation times of gene transcription also need to be considered in selecting the sampling frequency. Because changes in gene transcription have been observed over 2- to 6-h periods (Hirahara et al. 2001; Gill et al. 2002), a 20-min sampling was deemed sufficient to provide a high enough resolution to accurately assess system responses on this time scale. We note that we cannot accurately resolve higher frequency oscillatory reactions or discrete changes in transcription that respond in less than $20 \mathrm{~min}$, either directly to the change in light or indirectly to environmental or other gene regulatory changes affected by the light. In these cases, if the sampling frequency is not an even multiple of the response period, or if the overall response is transient over the length of the perturbation, poor correlations may be obtained (falsenegatives), or high correlations to the wrong stimuli (falsepositives). Additionally, more complex analyses meant to uncover multi-gene interactions occurring within these experiments are certainly possible. Information-theory approaches (D'Haeseleer et al. 1998) could be adapted to include time-lag components to search for such relationships, but practical implementation of such an algorithm requires substantial additional effort and is outside of the scope of this project.

\section{DISCUSSION}

We have conducted two time-series DNA microarray experiments, one with 47 measurements (of 50 time points) taken over $17 \mathrm{~h}$, and another of 27 measurements taken over $9 \mathrm{~h}$. Both of these experiments share the same sampling interval (20 min) and are taken from single, homogeneous (well-stirred) cultures. These experiments are especially unique because of the application of an instantaneous forcing environmental input, the intensity of the incident light to the system. Compared to earlier time-series experiments with DNA microarrays (Chu et al. 1998; Spellman et al. 1998; Iyer et al. 1999; Hihara et al. 2001; Gill et al. 2002), these experiments possess a much higher, and evenly spaced, sampling frequency. These experimental parameters were specifically designed to enable the use of time-lagged correlations that could identify directional transcriptional relationships on a 20-min time scale.

Time-lagged correlations (Arkin and Ross 1995) provide a reasonable method for extracting potential relationships within the genetic network, and we have detailed our adjustments for practical implementation to such large data sets that contain significant obscuring error. For the time-interval studied, these correlations manifest themselves as "waves" of expression in Synechocystis sp. lagged at different intervals from the changing light intensity. Larger intervals would have allowed, for the same number of experiments, study of a longer cycle of transcriptional events, with loss of resolution between time-scales (i.e., a 40-min sampling period cannot distinguish between 20-, 40-, and 60min lag times). Similarly, for greater resolution into the ordering of transcriptional events, smaller time-scales than those attempted here may be tried, with the accompanying increase in required arrays.

\section{Genome Research}

www.genome.org 


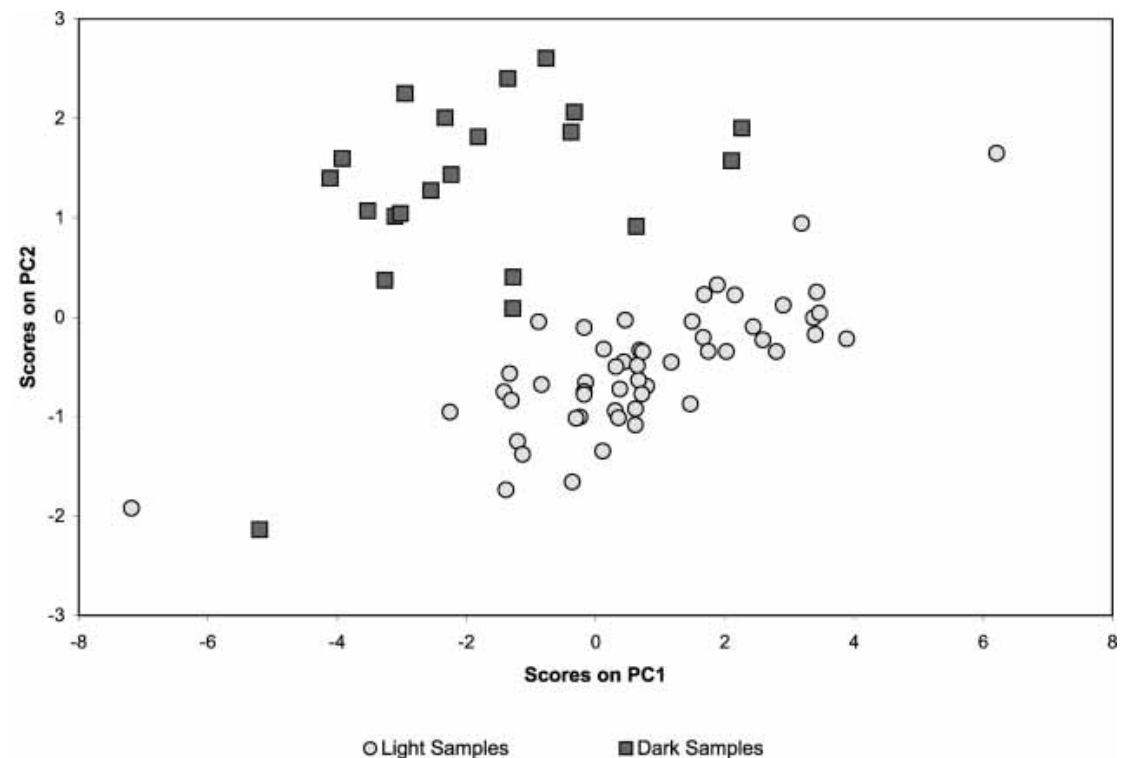

Figure 5 Two-dimensional mean-centered Principle Components Analysis of all 74 time points, using only the 113 genes.

Although a substantial effort is required to plan and perform this type of experiment, an enormous amount of information is obtained. This information enables the construction of genetic networks using the system's identification technique of timelagged correlations. The directionality of the resulting networks provides more information than clustering alone, and therefore allows the researcher to generate hypotheses based on the system structure. Additionally, it is important to consider similarly expressed genes as potential regulon members. Regulons are sets of coregulated genes with common promoter regions differing from operons in that they are not necessarily sequentially oriented in the genome. To this end, genes with the same time-lagged correlation may be considered as good regulon candidates.

The 50 groups containing 259 genes uncovered by this analysis technique (Table 1) contained genes that are known to have light-induced regulation, as well as unannotated genes, whose functions have yet to be completely assessed. The former group, containing genes such as $a p c F, a p c E$, and $a p c A B C$, demonstrate the reliability of the technique, while the latter group can help formulate testable hypotheses for a gene's function. This suggests that dynamic studies of transcriptional behavior with significant numbers of time-points can play a key role in understanding cellular regulation. As other measurements such as protein and metabolite data become available at similar scales and frequencies as DNA microarray data, then time-lagged correlation studies should allow for the creation of hypothetical networks similar to Figures 3 and 4 that will contain greater degrees of mechanistic information. Such approaches will hold new insights into the regulation of Synechocystis and may contribute to its utilization for carbon fixation at a practical scale.

\section{METHODS}

\section{Time-Lagged Correlation Methodology}

To analyze DNA microarray data using time-lagged correlations, some adjustments were made to the method described by Arkin et al. (Arkin and Ross 1995; Arkin et al. 1997). Because we are interested in the transcriptional response to a single perturbation in the experimental system, the input light intensity profile was used as a "seed" in the search for genes with correlated time-lagged expression profiles. This seed profile consists of the autoscaled light intensity values at each time point. It is the initial profile to which the autoscaled dynamic gene transcription profiles are compared to determine their level of correlation in the first iteration of the algorithm. The following steps were then used to perform the network reconstruction effort.

\section{Step 1: Filter Low-Signal Genes and Cluster Potential Operon Members}

Some microarray genes (or features) may not exhibit significant expression levels under the conditions investigated. Such genes unnecessarily complicate the computations and are easily removed by the application of filters requiring not only significant expression levels but also significant changes in expression. Genes that did not have an experimental signal intensity significantly above the background variation for at least half of the time points in a given experiment were excluded from further consideration. Also, all genes without a significant expression change (defined as a twofold increase or decrease) for at least one time-point were eliminated from further analysis. In these experiments the filters typically eliminated approximately $25 \%$ of the microarray features from further consideration.

Because the Synechocystis genome has been sequenced, additional information is available about each gene's chromosomal location and relative ordering within the genome (http:// www.kazusa.or.jp/cyano/). This information, along with the experimental expression data, may suggest the existence of operons, or coexpressed sets of genes due to a common upstream promoter system. In this algorithm, instead of traditional clustering (Dillon and Goldstein 1984; Kamimura 1997; Eisen et al. 1998; Heyer et al. 1999; Tamayo et al. 1999; Zhu and Zhang 2000), genes that are located adjacent to one another in the genome were analyzed for correlation of expression with zero timelag. Those that correlated, $|\mathbf{R}(\tau)|>0.7$, were grouped into clusters. The average autoscaled profile of the gene cluster was calculated to represent the entire group of adjacent genes.

\section{Step 2: Correlate Gene Expression Profiles With the Input Signal}

After applying the filters in Step 1, all genes and gene clusters were subsequently analyzed for their time-lagged correlation with the input signal. In subsequent iterations, the network can be expanded by substituting the gene groups from Step 3 for the input signal used in this step.

Recall that the correlation of equations 1 and 2 comparing the input signal in the first iteration (or the average profile of a gene cluster in subsequent iterations), $i$, to gene $j$ best identifies relationships of the type

$$
g_{i}(t)=A g_{j}\left(t-\tau_{0}\right)+B
$$

Substituting this relationship into the correlation equations shows that a maximum $S_{i j}$ value will occur at $\tau=-\tau_{0}$. At this point $S_{i j}=A \cdot \sigma_{j}$, where $\sigma_{j}$ is the variance of $g_{j}$, which corresponds to $r_{i j}=1$. Because gene expression is affected by a variety of variables, some of which are not accounted for, the resulting pairwise-correlations will often be less than unity. This suggests that key genes will possess strong but imperfect correlation with the input signal. By lowering the threshold values for $r_{i j}$ from unity, such imperfect correlations with appropriate time lags can be captured. All genes having at least one $r(\tau)$ value greater than the preselected cutoff of $|\mathbf{R}|>0.7$, were set aside for further consid- 
Table 2. The Maximum " $R$ " Values and Corresponding Time Lags for Those Groups Directly Correlated With Light Intensity in Figure 3

\begin{tabular}{|c|c|c|c|}
\hline \multirow[b]{2}{*}{ Gene } & \multicolumn{2}{|c|}{ Expt 1} & \multirow{2}{*}{$\begin{array}{l}\text { Expt } 2 \\
\text { R_value }\end{array}$} \\
\hline & R_value & lag & \\
\hline ycf59 & 0.7076 & -1 & 0.8459 \\
\hline sll1213 & 0.6528 & -1 & 0.6282 \\
\hline \multirow[t]{2}{*}{ atpC } & 0.7104 & -2 & 0.6834 \\
\hline & 0.6954 & -1 & 0.5538 \\
\hline atpA & 0.7621 & -1 & 0.7062 \\
\hline atpD & 0.7656 & -1 & 0.6996 \\
\hline atpF & 0.7887 & -1 & 0.7376 \\
\hline atpG & 0.7923 & -1 & 0.7986 \\
\hline atpH & 0.7515 & -1 & 0.726 \\
\hline atpl & 0.7174 & -1 & 0.7129 \\
\hline atp1 & 0.6957 & -1 & 0.6956 \\
\hline ssr2998 & 0.7368 & -1 & 0.5498 \\
\hline sll0927 & 0.7577 & -1 & 0.7832 \\
\hline ycf48 & 0.6153 & -1 & 0.617 \\
\hline psbE & 0.773 & -1 & 0.8076 \\
\hline psbF & 0.6935 & -1 & 0.7679 \\
\hline psbL & 0.7051 & -1 & 0.7225 \\
\hline \multirow[t]{2}{*}{ psb] } & 0.6534 & -3 & 0.4751 \\
\hline & 0.6454 & -1 & 0.4812 \\
\hline sll1070 & 0.7236 & -1 & 0.5628 \\
\hline sll1069 & 0.6787 & -1 & 0.5806 \\
\hline acp & 0.7625 & -1 & 0.734 \\
\hline pphA & 0.737 & -1 & 0.3616 \\
\hline арсA & 0.7081 & -1 & 0.7729 \\
\hline \multirow[t]{2}{*}{ apcB } & 0.7122 & -2 & 0.7714 \\
\hline & 0.7101 & -1 & 0.7686 \\
\hline apcC & 0.7757 & -1 & 0.7301 \\
\hline atpB & 0.6959 & -1 & 0.7359 \\
\hline atpE & 0.7519 & -1 & 0.7067 \\
\hline slr1331 & 0.6175 & -1 & 0.5313 \\
\hline slr1336 & 0.7095 & -1 & 0.4099 \\
\hline nbpl & 0.7482 & -1 & 0.6761 \\
\hline chIP & 0.792 & -1 & 0.8206 \\
\hline psaE & 0.7258 & -1 & 0.626 \\
\hline fpg & 0.5831 & -1 & 0.4718 \\
\hline slr0447 & 0.7872 & -1 & 0.7425 \\
\hline pgk & 0.7521 & -1 & 0.7304 \\
\hline slr0193 & 0.7216 & -1 & 0.6682 \\
\hline rpiA & 0.6194 & -1 & 0.4247 \\
\hline sll0822 & 0.7776 & -1 & 0.7791 \\
\hline ssl1263 & 0.7031 & -1 & 0.7185 \\
\hline slr0967 & -0.8524 & -1 & -0.8587 \\
\hline sll1515 & -0.7392 & -1 & -0.8205 \\
\hline sll1009 & -0.7878 & -1 & -0.273 \\
\hline ssl1911 & -0.7832 & -1 & -0.8907 \\
\hline slr1232 & -0.7922 & -1 & -0.8773 \\
\hline ssr2078 & -0.7062 & -1 & -0.7272 \\
\hline slr1712 & -0.7016 & -1 & -0.6647 \\
\hline ssr2227 & -0.8571 & -1 & -0.9117 \\
\hline slr0822 & -0.7292 & -1 & -0.7255 \\
\hline ssr0692 & -0.7791 & -1 & -0.8701 \\
\hline slr0581 & -0.7666 & -1 & -0.5221 \\
\hline slr0582 & -0.6686 & -1 & -0.4439 \\
\hline slr0518 & -0.7619 & -1 & -0.9146 \\
\hline ssl0832 & -0.7446 & -1 & -0.9486 \\
\hline slr0587 & -0.7757 & -1 & -0.8677 \\
\hline$g \ln A$ & 0.0744 & -1 & 0.7902 \\
\hline sll1835 & 0.7433 & -1 & 0.7475 \\
\hline guaA & 0.706 & -1 & 0.6698 \\
\hline hemE & 0.7058 & -1 & 0.6841 \\
\hline gap2 & 0.8028 & -1 & 0.7914 \\
\hline slr1431 & 0.7106 & -1 & 0.7032 \\
\hline apcF & 0.7222 & -1 & 0.7767 \\
\hline $\operatorname{argG}$ & 0.7397 & -1 & 0.7682 \\
\hline срсC2 & 0.6376 & -2 & 0.2069 \\
\hline срсA & 0.7095 & -2 & 0.4941 \\
\hline срсB & 0.7299 & -2 & 0.593 \\
\hline
\end{tabular}

Genes with similar " $R$ " values at different time-lags were placed in Figure 3 by consensus of the group, and the corresponding " $R$ " values are also listed. eration. In this way, a set of "first-order" interactions was obtained in a computational time increasing linearly with the number of genes included.

Using simulations, we found that the determination of time-lags and correlations is highly dependent on perturbations in the experimental conditions that lead to measurable changes in gene transcription. This has also been noted by Arkin and Ross (1995) who suggest continuous perturbation of the system away from steady-state to discover the underlying system structure. Thus, all experiments in our studies were conducted under dynamic conditions, with the data collected at homogenously spaced sampling intervals.

\section{Step 3: Assemble Groups Containing Retained Genes From Step 2}

In this step, the retained genes were sorted by their time-lag correlations with the input signal-all genes that best correlated with lags of one interval were put into one category, lags of two intervals into a second category, etc. After grouping the genes according to their time-lags, a nearest-neighbor (Dillon and Goldstein 1984) clustering scheme was implemented within each group using correlation with no time-lag zero as the definition of similarity. In other words, each gene was compared to all other genes within each group, and the highest correlated genes were assembled into sub-groups. This procedure was repeated until the correlation between groups fell below the preselected cutoff value, $|\mathbf{R}|>0.7$ (as in Step 2). In this way we partition the original time-lagged groups into subgroups based on clustering. The difference between these subgroups is at least as strong as the differences between the correlated and uncorrelated genes found in Step 2.

\section{Step 4: Expand the Network by Repeating Steps 2 and 3}

Each of the discovered groups can be used as a "seed" node in the same way the input signal (i.e., light intensity) was used in Step 2 to expand the network. In general, the correlation threshold could be selected to either encourage inclusion of genes into the network or promote exclusion and focus on "core" interactions. If the cutoff is chosen too low, however, the network could expand to include thousands of genes. For our studies, more stringent cutoffs at a value of 0.7 were used to limit the size of the resulting networks.

\section{Step 5: Create a Graphical Representation of the Network}

For small data sets the interaction network may be analyzed and visualized manually; however, for larger systems this process needs to be automated. The Graphviz program from ATT Research Labs (http://www.research.att.com/sw/tools/graphviz/) was adapted for this purpose. This program has been optimized using heuristics to minimize cross-over events between edges in order to create easily interpreted output figures. For our purposes, the output of our analysis software (written in MatLab) has been written into simple text code that is reinterpreted to create jpeg images. MatLab functions for automating the creation of such files from time-lagged correlation analysis have been written for this purpose and are available from the author, along with the data sets (http://web.mit.edu/cheme/gnswebpage/index.shtml) and time-lagged correlation algorithm files.

\section{Experimental Conditions}

Synechocystis can grow on a variety of carbon sources including glucose or $\mathrm{CO}_{2}$. For all of the studies conducted here, cells were grown solely on dissolved $\mathrm{CO}_{2}$ as $\mathrm{HCO}_{3}^{-}$. Other medium requirements, such as a source of nitrogen and salts, were provided using BG-11 medium (Sigma), designed specifically to satisfy the nutritional needs of freshwater cyanobacteria. All cultures were grown in an incubator at $30^{\circ} \mathrm{C}$ under fluorescent light. Light intensity in the incubator was determined to be approximately 6900 LUX, or a photosynthetic photon flux (PPF) of about 90 $\mu \mathrm{mol} / \mathrm{m}^{2} / \mathrm{s}$ at the surface of a culture. This flux is expected to drop significantly inside of the cultures due to shielding by the outermost cells; therefore all cultures were continuously shaken or stirred to ensure homogeneity of light exposure.

\section{Genome Research}


Table 3. Gene Groups for the Network of Figure 4.

\begin{tabular}{|c|c|c|c|c|c|c|c|c|c|c|c|}
\hline $\begin{array}{l}\text { Group 2 } \\
\text { ycf59 } \\
\text { atpC } \\
\text { atpD } \\
\text { atpG } \\
\end{array}$ & $\begin{array}{l}\text { sll1213 } \\
\text { atpA } \\
\text { atpF } \\
\text { atpH }\end{array}$ & $\begin{array}{l}a t p l \\
a t p L\end{array}$ & & $\begin{array}{l}\text { Group 3 } \\
\text { sllog27 } \\
\text { pphA } \\
\text { fpg } \\
\text { ssr2998 } \\
\end{array}$ & $\begin{array}{l}y c f 48 \\
\text { apcA } \\
\text { sirO447 } \\
a c p \\
\end{array}$ & $\begin{array}{l}p s b E \\
a p c B \\
p g k \\
p s a E\end{array}$ & $\begin{array}{l}\rho s b F \\
a p c C \\
n b p l \\
\text { sllo822 } \\
\end{array}$ & $\begin{array}{l}p s b L \\
\text { atpB } \\
\text { chIP }\end{array}$ & $\begin{array}{l}\text { psbJ } \\
\text { atpE } \\
\text { sirot93 }\end{array}$ & $\begin{array}{l}\text { sll1070 } \\
\text { slrt331 } \\
\text { rpiA }\end{array}$ & $\begin{array}{l}\text { sll1069 } \\
\text { sir1336 } \\
\text { ssi1263 }\end{array}$ \\
\hline \begin{tabular}{|l} 
Group 4 \\
siro967 \\
sir 1232 \\
siro822
\end{tabular} & $\begin{array}{l}\text { s/l1515 } \\
\text { ssr2078 } \\
\text { ssr0692 }\end{array}$ & $\begin{array}{l}\text { s/l1009 } \\
\text { slr1712 } \\
\text { slr0581 }\end{array}$ & $\begin{array}{l}\text { ss } 10832 \\
\text { ssr2227 } \\
\text { siro518 }\end{array}$ & $\begin{array}{l}\text { sir0587 } \\
\text { sir0582 } \\
\text { ssl1911 } \\
\end{array}$ & & $\frac{\text { Group } 5}{\operatorname{gin} A}$ & & $\begin{array}{l}\text { Group } 6 \\
\text { sli1835 } \\
\text { hemE }\end{array}$ & $\begin{array}{l}\text { guaA } \\
\text { gap2 }\end{array}$ & $\begin{array}{l}\text { sir7431 } \\
\arg G\end{array}$ & $a p c F$ \\
\hline $\begin{array}{l}\text { Group } 7 \\
C D c A\end{array}$ & $c p c B$ & $c p c C 2$ & & $\begin{array}{l}\text { Group 8 } \\
\text { rp/19 } \\
\text { s/11130 }\end{array}$ & $\begin{array}{l}\text { fus } \\
\text { apcE }\end{array}$ & $\begin{array}{l}\text { ssi2245 } \\
\text { tufA }\end{array}$ & $\begin{array}{l}\text { efp } \\
\text { sir0752 } \\
\end{array}$ & rpsla & $a c c B$ & $s / 1234$ & $i N C$ \\
\hline \begin{tabular}{|l} 
Group 9 \\
bioB \\
clpP \\
ctpA \\
icd \\
ppa \\
$p s a D$ \\
\end{tabular} & $\begin{array}{l}\rho s b K \\
\rho u r D \\
r b c L \\
r f b C \\
r p s+1 \\
\text { secD } \\
\end{array}$ & $\begin{array}{l}g y r B \\
\text { ndhH } \\
\text { nirA } \\
r b c X \\
\text { rbe } \\
\text { rpoC1 } \\
\end{array}$ & $\begin{array}{l}g p \times 1 \\
\text { hemB } \\
\text { murC } \\
\text { petH } \\
\text { rbcS } \\
\text { ifbF } \\
\end{array}$ & $\begin{array}{l}\text { sir1020 } \\
\text { sir1063 } \\
\text { sirf176 } \\
\text { sir1277 } \\
\text { sir1617 } \\
\text { sirf } 1770 \\
\end{array}$ & $\begin{array}{l}\text { sir1535 } \\
\text { sir1618 } \\
\text { sir1623 } \\
\text { sir1855 } \\
\text { sir2002 } \\
\text { trpB } \\
\end{array}$ & $\begin{array}{l}\text { sir1160 } \\
\text { sir1237 } \\
\text { sir1619 } \\
\text { sir1624 } \\
\text { vals } \\
\text { yci23 }\end{array}$ & $\begin{array}{l}\text { sir1052 } \\
\text { sir1062 } \\
\text { sir1276 } \\
\text { sir1363 } \\
\text { sir1616 } \\
\text { thic }\end{array}$ & $\begin{array}{l}\text { rps20 } \\
\text { SerA } \\
\text { slr0483 } \\
\text { sir0773 } \\
\text { ycf3 } \\
\text { rbG }\end{array}$ & $\begin{array}{l}\text { sir0981 } \\
\text { sir1050 } \\
\text { sir1177 } \\
\text { sir1349 } \\
\text { trpE } \\
\text { sir0484 }\end{array}$ & $\begin{array}{l}\text { rps13 } \\
\text { secF } \\
\text { sir0982 } \\
\text { sirt051 } \\
\text { sirt105 }\end{array}$ & $\begin{array}{l}\text { pl136 } \\
\text { s/l1665 } \\
\text { sl11945 } \\
\text { sll1951 } \\
\text { sir0776 }\end{array}$ \\
\hline \begin{tabular}{|l|} 
Group 10 \\
s/l0843 \\
\end{tabular} & sll0842 & & $\begin{array}{l}\text { Group 11 } \\
\text { psaC }\end{array}$ & psaF & psad & & \begin{tabular}{|l} 
Group 12 \\
cupB \\
ysf58 \\
gylA \\
crtQ-2 \\
\end{tabular} & $\begin{array}{l}\text { sir2046 } \\
\text { cpcG1 } \\
\text { sil1921 } \\
\text { sir1462 }\end{array}$ & $\begin{array}{l}\text { sir2047 } \\
\text { sir2052 } \\
\text { pacs } \\
\text { fus }\end{array}$ & $\begin{array}{l}\text { sir2048 } \\
\text { dnak } \\
\text { sir2025 }\end{array}$ & $\begin{array}{l}\text { sigA } \\
\text { sir0654 } \\
\text { sir1464 }\end{array}$ \\
\hline \begin{tabular}{|l} 
Group 13 \\
$p s b M$
\end{tabular} & & \begin{tabular}{|l} 
Group 14 \\
$\operatorname{sir} 1066$ \\
\end{tabular} & sir1070 & sirto73 & sir1071 & sir1072 & & \begin{tabular}{|l|} 
Group 15 \\
$\operatorname{cpcD}$ \\
\end{tabular} & & $\begin{array}{l}\text { Group 16 } \\
\text { s/11268 }\end{array}$ & \\
\hline $\begin{array}{l}\text { Group } 17 \\
\text { ssr1480 }\end{array}$ & & $\begin{array}{l}\text { Group } 18 \\
\text { ribF } \\
\end{array}$ & $n d b B$ & & $\begin{array}{l}\text { Group } 19 \\
\text { petG }\end{array}$ & sslo294 & & $\frac{\text { Group 20 }}{\text { petF }}$ & & $\begin{array}{l}\text { Group 21 } \\
p s b X\end{array}$ & \\
\hline$\frac{\text { Group 22 }}{\text { sirt068 }}$ & & \begin{tabular}{|l} 
Group 23 \\
sirt396
\end{tabular} & & \begin{tabular}{|l} 
Group 24 \\
siro709
\end{tabular} & & \begin{tabular}{|l} 
Group 25 \\
psaK
\end{tabular} & rps32 & psal & psbl & psal & \\
\hline $\begin{array}{l}\text { Group 26 } \\
\text { ssl2009 }\end{array}$ & & $\begin{array}{l}\text { Group 27 } \\
\text { rps } 15 \\
\end{array}$ & & \begin{tabular}{|l} 
Group 28 \\
s/11837 \\
siroo82 \\
ssl2874 \\
rplat
\end{tabular} & $\begin{array}{l}\text { sil1712 } \\
\operatorname{rps} 4 \\
\text { sir1406 }\end{array}$ & $\begin{array}{l}\text { gapf } \\
\text { ndhJ } \\
\text { ssrt528 }\end{array}$ & $\begin{array}{l}\text { s/ri821 } \\
\text { s/ri282 } \\
\text { ss/1046 }\end{array}$ & $\begin{array}{l}\text { silf } 1979 \\
\text { rpl21 } \\
\text { siroo73 }\end{array}$ & $\begin{array}{l}\text { siro82f } \\
\text { siro294 } \\
\text { siro765 }\end{array}$ & $\begin{array}{l}\text { ss } 10242 \\
\text { s/roo38 } \\
\text { s/r1338 }\end{array}$ & $\begin{array}{l}\text { rps21 } \\
\text { siroo39 } \\
\text { sll1343 }\end{array}$ \\
\hline $\begin{array}{l}\text { Group 29 } \\
\text { sers } \\
\end{array}$ & $\mathrm{ccmK}$ & nate & & \begin{tabular}{|l} 
Group 30 \\
sll1721 \\
\end{tabular} & & \begin{tabular}{|l|} 
Group 31 \\
sodB \\
\end{tabular} & & \begin{tabular}{|l} 
Group 32 \\
siros16 \\
\end{tabular} & $p s b B$ & sir0907 & \\
\hline \begin{tabular}{|l} 
Group 33 \\
$p p p A$ \\
\end{tabular} & $s / 11386$ & & \begin{tabular}{|l|} 
Group 34 \\
ssr2130 \\
\end{tabular} & & $\begin{array}{l}\text { Group } 35 \\
\text { sllo264 } \\
\text { silo096 } \\
\end{array}$ & $\begin{array}{r}\text { sllo135 } \\
\text { sllo163 } \\
\end{array}$ & $\begin{array}{l}\text { hemD } \\
\text { slloo63 }\end{array}$ & $\begin{array}{l}s 110350 \\
s / 10062 \\
\end{array}$ & $\begin{array}{l}\text { sir0232 } \\
\text { silloo86 }\end{array}$ & $\begin{array}{l}\text { sllo064 } \\
\text { slloo85 }\end{array}$ & sll0103 \\
\hline \begin{tabular}{|l} 
Group 36 \\
sir1926 \\
\end{tabular} & ndhD1 & stro476 & & \begin{tabular}{|l} 
Group 37 \\
sir0784 \\
\end{tabular} & & \begin{tabular}{|l|} 
Group 38 \\
sir2010 \\
\end{tabular} & & \begin{tabular}{|l} 
Group 39 \\
sir0886 \\
\end{tabular} & $\operatorname{gin} B$ & & \begin{tabular}{|l} 
Group 40 \\
sir 4410
\end{tabular} \\
\hline \begin{tabular}{|l} 
Group 41 \\
sirt964
\end{tabular} & & \begin{tabular}{|l} 
Group 42 \\
ssi1792 \\
\end{tabular} & & \begin{tabular}{|l} 
Group 43 \\
siro915 \\
\end{tabular} & & \begin{tabular}{|l|} 
Group 44 \\
slrog21 \\
\end{tabular} & & \begin{tabular}{|l} 
Group 45 \\
hisD \\
\end{tabular} & pxcA & & $\begin{array}{l}\text { Group 46 } \\
\text { hspA }\end{array}$ \\
\hline $\begin{array}{l}\text { Group } 47 \\
\text { rol24 }\end{array}$ & & $\begin{array}{l}\text { Group 48 } \\
\text { s/r2115 }\end{array}$ & & \begin{tabular}{|l} 
Group 49 \\
$y c f 46$ \\
\end{tabular} & & $\begin{array}{l}\text { Group } 50 \\
\text { ssi1045 } \\
\end{array}$ & & & & & \\
\hline
\end{tabular}

Seed cultures were used to inoculate intermediate cultures, which fed the reactor vessel. Seed cultures were grown in 250-ml flasks with cotton and gauze caps and contained $100 \mathrm{ml}$ of $\mathrm{H}_{2} \mathrm{O}$ that was heat sterilized. Concentrated (50X) BG-11 medium (2 $\mathrm{ml})$ and $0.38 \mathrm{M} \mathrm{Na}_{2} \mathrm{CO}_{3}(300 \mu \mathrm{l})$ were added to the cooled $\left(30^{\circ} \mathrm{C}\right.$ maximum) flasks. Intermediate cultures used to inoculate the larger reactor vessels were grown in 1-L flasks with $300 \mathrm{ml}$ of $\mathrm{H}_{2} \mathrm{O}$. Concentrated (50X) BG-11 (6 ml) and $0.38 \mathrm{M} \mathrm{Na}_{2} \mathrm{CO}_{3}(300$ $\mu \mathrm{l}$ ) were added to the flasks, along with sterile-filtered $1 \mathrm{M}$ HEPES $(6 \mathrm{ml})$ to create an environment similar to the sparged reactor vessel (see below). Approximately $10 \mathrm{ml}$ from a 250-ml seed culture in late-exponential or stationary phase was used for inoculation of the intermediate cultures. Intermediate cultures were grown to mid-exponential phase $\left(\mathrm{A}_{730} \sim 1.0\right.$, approximately 4 days) before inoculating the large reactors.

The layout of the sparged-gas vessel is shown in Figure 2. Six liters of $\mathrm{H}_{2} \mathrm{O}$ was autoclaved in the 10- $\mathrm{L}$ reactor vessel with a large stir-bar placed in the center of the gas-sparging ring. Since $\mathrm{CO}_{2}$ was bubbled through this reactor, no $\mathrm{Na}_{2} \mathrm{CO}_{3}$ was added, only BG-11 media $(120 \mathrm{ml})$. Dissolved $\mathrm{CO}_{2}$ gas in the form of $\left(\mathrm{H}^{+}\right)\left(\mathrm{HCO}_{3}^{-}\right)$increases the acidity of the culture, drastically inhibiting growth. To counteract this, $1 \mathrm{M}$ HEPES $(120 \mathrm{ml})$ was added as a $\mathrm{pH}$ buffer $\left(\mathrm{pKa}=7.31\right.$ at $\left.37^{\circ} \mathrm{C}\right)$. The $\mathrm{CO}_{2}$ source gas (1-3\% $\mathrm{CO}_{2}, \sim 16 \% \mathrm{O}_{2}$, balance $\mathrm{N}_{2}$ ) flowed through a sterile filter into a plastic tubing ring sparger at a rate of about $150 \mathrm{ml} / \mathrm{min}$. Sparged gas escaped through a pressure release valve 
at the top of the vessel. A final tube, extending deep into the liquid culture, was sealed with a quick-release and used for sampling.

All experiments were conducted as described in Schmitt Jr. and Stephanopoulos (2003). The experimental setup and light intensity profiles are shown in Figure 2 . To ensure that the cells never reached a steady state, the input intensity of light was changed every $3 \mathrm{~h}$ for the first experiment. The three light intensities shown correspond to 0,16 , and $90 \mu \mathrm{mol} / \mathrm{m}^{2} / \mathrm{s}$ photosynthetic photon flux (PPF). Culture samples were taken in tubes containing 10\% of a phenol (5\%) and ethanol (95\%) mixture and immediately chilled, but not frozen, in liquid nitrogen. These samples were centrifuged at $5000 \times \mathrm{g}$ for $5 \mathrm{~min}$ at $2^{\circ} \mathrm{C}$, and the resulting pellets were stored at $-80^{\circ} \mathrm{C}$ until isolating the RNA.

To isolate the RNA, pellets were resuspended and processed according to the Qiaquick (Qiagen) RNA extraction kit, with the additional step of grinding the cell pellets in a bead mill for 4 min to break the Synechocystis' outer cell wall. Typical yields were $10-50 \mu \mathrm{g}$ of RNA for 50-ml tubes of samples, which is enough to run between one and four microarrays.

Full-length cDNA microarrays (provided by DuPont Co. comprising 3078 unique cDNA sequences were used. These were shipped dry in 384 well $(16 \times 24)$ plates (Genetix), resuspended with $5 \mu \mathrm{l}$ of $50 \%$ (vol.) DMSO in $\mathrm{H}_{2} \mathrm{O}$, and stored at $-80^{\circ} \mathrm{C}$ until printing. Arrays were printed on a MicroGrid II quill pin microarrayer (BioRobotics) at $35-45 \%$ relative humidity at room temperature on Corning Gap slides. Sixteen quill pins were used to print with a 0.29 pitch $(290 \mu \mathrm{m}$ spacing) between features. The features were printed in 16 grids, each containing 15 rows and 15 columns of cDNA features. While printing, each pin was blotted three times on each of four spare slides to remove excess liquid from the quills. Then printing was performed at one tap/slide for each of 104 slides. This entire procedure was repeated on the bottom half of each slide. The printing procedure took about $20 \mathrm{~h}$ to print the entire cDNA library in duplicate on 104 slides. Slides were then crosslinked in batches of 18 slides using a Stratalinker (Stratagene) set to the "Autocrosslink" option at $1200 \mu \mathrm{J}$, and were stored in the dark until use.

All RNA samples were processed into labeled cDNA, hybridized to arrays, and scanned as described in Schmitt Jr. and Stephanopoulos (2003). To summarize the results of that paper, data from this experiment was used to build AutoRegressive with eXogeneous input (ARX; Wei 1990; Schmitt Jr. and Stephanopoulos 2003) models to predict the transcriptional outcome of various potential follow-up experiments. The profile selected as most likely to contain discriminating information was used as the input light signal for the second experiment, also shown in Figure 2. Details of this experimental design procedure are also contained in Schmitt Jr. and Stephanopoulos (2003).

Microarray quality, sample processing, and data filters were analyzed in aggregate by hybridizing six samples from cultures grown in parallel and labeled with different dyes to three microarrays. On average, the expression ratio of $8.8 \%$ genes differed by greater than 1.75 , while only $5.1 \%$ of genes differed by more than twofold, consistent with other cDNA microarray experiments. Based on these results, genes were deemed to be differentially expressed if they exhibited an expression ratio of twofold or greater with respect to the control. A compilation of all duplicate spots within slides gave a within-slide coefficient of variation of 0.18 .

\section{ACKNOWLEGMENTS}

Data and computer files are available from the corresponding author. This work was supported by NSF grant number BES9985421 . Additional support was provided by NIH grant number 1-RO1-DK58533-01. PCR products for the construction of the whole genome microarrays of Synechocystis were provided by the DuPont Company. Their assistance in this research, in particular Drs. Lisa Hwang and Ethel Jackson, is gratefully acknowledged.
The publication costs of this article were defrayed in part by payment of page charges. This article must therefore be hereby marked "advertisement" in accordance with 18 USC section 1734 solely to indicate this fact.

\section{REFERENCES}

Alter, O., Brown, P.O., and Botstein, D. 2000. Singular value decomposition for genome-wide expression data processing and modeling. Proc. Natl. Acad. Sci. 97: 10101-10106.

Arkin, A. and Ross, J. 1995. Statistical construction of chemical-reaction mechanisms from measured time-series. J. Phys. Chem. 99: 970-979.

Arkin, A., Shen, P.D., and Ross, J. 1997. A test case of correlation metric construction of a reaction pathway from measurements. Science 277: $1275-1279$.

Bryant, D.A., Delorimier, R., Guglielmi, G., and Stevens, S.E. 1990. Structural and compositional analyses of the phycobilisomes of Synechococcus sp Pcc 7002-Analyses of the wild-type strain and a phycocyanin-less mutant constructed by interposon mutagenesis. Arch. Microbiol. 153: 550-560.

Chu, S., DeRisi, J., Eisen, M., Mulholland, J., Botstein, D., Brown, P.O., and Herskowitz, I. 1998. The transcriptional program of sporulation in budding yeast. Science 282: 699-705.

D’Haeseleer, P., Wen, X., Fuhrman, S., and Somogyi, R. 1998. Mining the gene expression matrix: Inferring gene relationships from large scale gene expression data. In Information processing in cells and tissues (eds. R.C. Paton and M. Holcombe), pp. 203-212. Plenum, New York.

Dillon, W.R. and Goldstein, M. 1984. Multivariate analysis. Wiley, New York.

Eisen, M.B., Spellman, P.T., Brown, P.O., and Botstein, D. 1998. Cluster analysis and display of genome-wide expression patterns. Proc. Natl. Acad. Sci. 95: 14863-14868.

Friedman, N., Linial, M., Nachman, I., and Pe'er, D. 2000. Using Bayesian networks to analyze expression data. Fourth Annual International Conference on Computational Molecular Biology. Tokyo.

Gill, R.T., Katsoulakis, E., Schmitt, W., Taroncher-Oldenburg, G., Misra, J., and Stephanopoulos, G. 2002. Genome-wide dynamic transcriptional profiling of the light-to-dark transition in Synechocystis sp strain PCC 6803. J. Bacteriol. 184: 3671-3681.

Heyer, L.J., Kruglyak, S., and Yooseph, S. 1999. Exploring expression data: Identification and analysis of coexpressed genes. Genome Res. 9: $1106-1115$.

Hihara, Y., Kamei, A., Kanehisa, M., Kaplan, A., and Ikeuchi, M. 2001. DNA microarray analysis of cyanobacterial gene expression during acclimation to high light. Plant Cell 13: 793-806.

Holter, N.S., Mitra, M., Maritan, A., Cieplak, M., Banavar, J.R., and Fedoroff, N.V. 2000. Fundamental patterns underlying gene expression profiles: Simplicity from complexity. Proc. Natl. Acad. Sci. 97: 8409-8414.

Iyer, V.R., Eisen, M.B., Ross, D.T., Schuler, G., Moore, T., Lee, J.C.F., Trent, J.M., Staudt, L.M., Hudson, J., Boguski, M.S., et al. 1999. The transcriptional program in the response of human fibroblasts to serum. Science 283: 83-87.

Kamimura, R.T. 1997. "Application of multivariate statistics to fermentation database mining." Ph.D. thesis, Massachusetts Institute of Technology, Cambridge, MA.

Kaneko, T., Sato, S., Kotani, H., Tanaka, A., Asamizu, E., Nakamura, Y. Miyajima, N., Hirosawa, M., Sugiura, M., Sasamoto S., et al. 1996. Sequence analysis of the genome of the unicellular cyanobacterium Synechocystis sp. strain PCC6803. 2. Sequence determination of the entire genome and assignment of potential protein-coding regions. DNA Res 3: 109-136.

Kuruvilla, F.G., Park, P.J., Schreiber, S.L. 2002. Vector algebra in the analysis of genome-wide expression data. Genome Biol. 3: 0011.1-0011.11.

Meurer, J., Plucken, H., Kowallik, K.V., and Westhoff, P. 1998. A nuclear-encoded protein of prokaryotic origin is essential for the stability of photosystem II in Arabidopsis thaliana. Embo J. 17: 5286-5297.

Misra, J., Schmitt, W., Hwang, D., Hsiao, L.L., Gullans, S., Stephanopoulos, G. 2002. Interactive exploration of microarray gene expression patterns in a reduced dimensional space. Genome Res. 12: $1112-1120$

Raychaudhuri, S., Stuart, J.M., and Altman, R.B. 2000. Principal components analysis to summarize microarray experiments: Application to sporulation time series. Pacific Symposium on Biocomputing. Hawaii.

Schmitt Jr., W.A. and Stephanopoulos, G. 2003. Prescription of transcriptional profiles of Synechosystis PCC6803 by dynamic

\section{Genome Research}


autoregressive modeling of DNA microarray data. Biotechnol. Bioeng. 84: $855-863$.

Somogyi, R. and Fuhrman, S. 1997. Distributivity, a general information theoretic network measurement, or why the whole is more than the sum of its parts. The International Workshop on Information Processing in Cells and Tissues. Sheffield, UK.

Spellman, P.T., Sherlock, G., Zhang, M.Q., Iyer, V.R., Anders, K., Eisen, M.B., Brown, P.O., Botstein, D., and Futcher, B. 1998. Comprehensive identification of cell cycle-regulated genes of the yeast Saccharomyces cerevisiae by microarray hybridization. Mol. Biol. Cell 9: 3273-3297.

Tamayo, P., Slonim, D., Mesirov, J., Zhu, Q., Kitareewan, S., Dmitrovsky, E., Lander, E.S., and Golub, T.R. 1999. Interpreting patterns of gene expression with self-organizing maps: Methods and application to hematopoietic differentiation. Proc. Natl. Acad. Sci. 96: 2907-2912.

Watson, G.M.F. and Tabita, F.R. 1996. Regulation, unique gene organization, and unusual primary structure of carbon fixation genes from a marine phycoerythrin- containing cyanobacterium. Plant Mol. Biol. 32: 1103-1115.
Wei, W. Time series analysis. 1990. Addison-Wesley, Redwood City, CA. Wilde, A., Lunser, K., Ossenbuhl, F., Nickelsen, J., and Borner, T. 2001. Characterization of the cyanobacterial ycf37: Mutation decreases the photosystem I content. Biochem. J. 357: 211-216.

Zhu, J. and Zhang, M.Q. 2000. Cluster, function and promoter: Analysis of yeast expression array. Pacific Symposium on Biocomputing. Hawaii.

\section{WEB SITE REFERENCES}

http://www.research.att.com/sw/tools/graphviz/; AT\&T Labs, Graphviz. http://www.kazusa.or.jp/cyano/; CyanoBase: The Genome Database for Cyanobacteria.

http://web.mit.edu/cheme/gnswebpage/index.shtml; Bioinformatics and Metabolic Engineering Laboratory at MIT.

Received February 11, 2004; accepted in revised form April 22, 2004. 


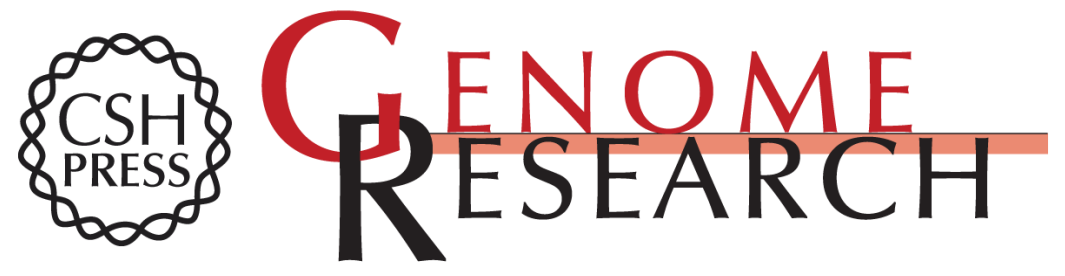

\section{Elucidation of Gene Interaction Networks Through Time-Lagged Correlation Analysis of Transcriptional Data}

William A. Schmitt, Jr., R. Michael Raab and Gregory Stephanopoulos

Genome Res. 2004 14: 1654-1663

Access the most recent version at doi:10.1101/gr.2439804

References This article cites 20 articles, 13 of which can be accessed free at:

http://genome.cshlp.org/content/14/8/1654.full.html\#ref-list-1

\section{License}

Email Alerting Receive free email alerts when new articles cite this article - sign up in the box at the Service top right corner of the article or click here.

\section{Affordable, Accurate Sequencing.}

